Thorax (1948), 3, 233.

\title{
THE CONTROL OF HAEMORRHAGE IN EXTRAPLEURAL PNEUMOTHORAX
}

\author{
BY
}

KENNETH S. MULLARD

Harefield and Hillingdon Hospitals

It is not the purpose of this short paper to discuss the indications for the use of extrapleural pneumothorax in the treatment of pulmonary tuberculosis. It is generally agreed that the procedure has a place in collapse therapy, and it is probable that this place would be larger if complications which not infrequently cause complete failure cou'd be avoided. The most frequent and most serious complications are haemorrhage into the space; tuberculous or non-tuberculous infection of the space; and early obliteration of the space by premature re-expansion of the lung. Haemorrhage into the space is often a precursor of the other complications, and if haemorrhage can be prevented a far larger number of successful cases will be obtained.

This paper describes a method by which haemorrhage has been prevented in all of the small number of cases in which it has been used. Reid (1946), describing a series of fifty-four personal cases, reported only one in which blood transfusion was required, but mentions that sometimes the extrapleural space was found completely opaque, with a crescentic lower margin, on the postoperative radiograph. This appearance was due to a haematoma filling the space, and it could be treated successfully by reopening and evacuating the clot. Unfortunately, Reid does not give the number of patients in whom this was necessary. Cleland (1948) states that moderate or massive haemorrhage occurs in from 5 to 20 per cent of the cases, and my own experience agrees with this rough figure, which is, however, optimistic. The true figure is much nearer 20 per cent than 5 per cent. No trouble has been experienced in the eleven cases now reported, and although this number is small the smooth postoperative course of these patients contrasts so strongly with the stormy and anxious times so often experienced with their predecessors that it seems worth while to publish the details of a simple and harmless procedure.

\section{The Use of Calcium Alginate}

Blaine (1947) has described the properties of alginic acid, a substance prepared by the hydrolysis of the brown seaweeds. The sodium salt, when acted upon by ionic calcium, forms instantly a clot of calcium alginate. This reaction takes place in very low concentrations; ten parts of 5 per cent sodium alginate in ninety parts of plasma are clotted by the addition of 0.5 per cent calcium chloride. The clot is absorbable in body tissues by a process of aseptic inflammation. It is also haemostatic. Calcium alginate gel, as it is called, can also be treated so that it can be woven into wool and gauze. All the substances can be sterilized by autoclaving at the temperatures and pressures normally used for sterilizing dressings.

It seemed likely that if an extrapleural space could be lined by a film of calcium alginate, postoperative reactionary haemorrhage would be prevented, and also the lung, covered by a supporting layer, would be prevented from re-expanding at least in the immediate postoperative period.

\section{The Operative Procedure}

The operative procedure is this: The extrapleural space is made in the usual way, stripping the parietal pleura to the level of the hilum of the lung medially, the seventh rib at the back, and the third rib in front. Haemorrhage is controlled by packing the space with hot, moist swabs, neither diathermy nor ligature being necessary. When the ooze has been controlled to the point when the space can be swabbed dry, and will remain dry for a minute or so, without more than a few $\mathrm{ml}$. of blood collecting at the bottom, then small gauze sponges on holders are soaked in a sterile 4 per cent solution of sodium alginate and are used to paint the entire walls of the space. This solution is viscous, about the consistency of office gum, and runs very slowly down the walls to the bottom; it is too thick to spray. As soon as the 
(a)

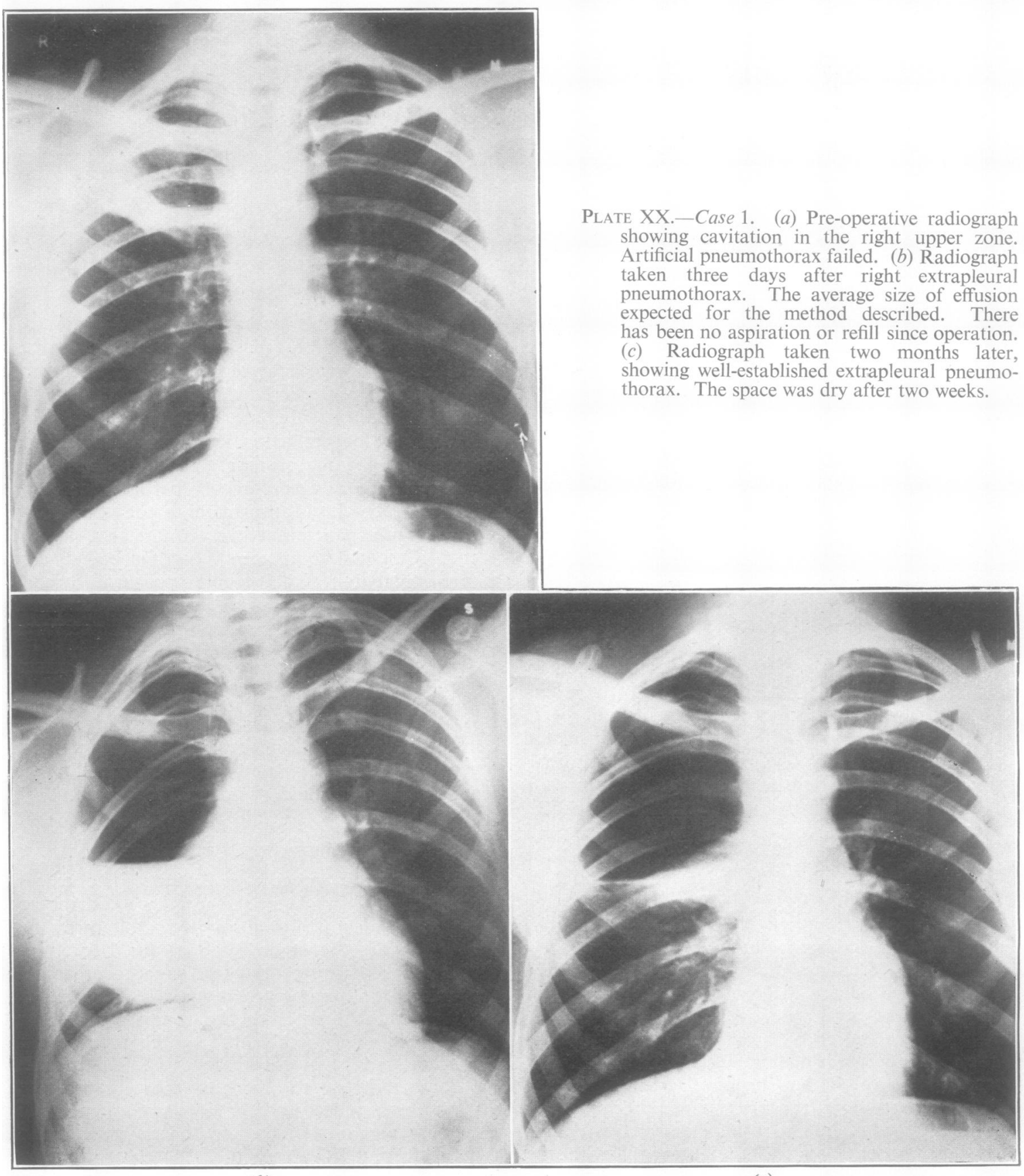

(b) showing cavitation in the right upper zone. Artificial pneumothorax failed. (b) Radiograph taken three days after right extrapleural has been no aspiration or refill since operation. (c) Radiograph taken two months later, showing well-established extrapleural pneumothorax. The space was dry after two weeks. 
Plate XXI.-Case 2. (a) Pre-operative radiograph Left artificial pneumothorax was performed in August, 1946, and one on the right was attempted in April, 1948. There was a cavity in the right upper zone. (b) Radiograph taken three days after operation. Effusion has not been aspirated and no refills have been given since operation. (c) Radiograph taken seven weeks later showing well-established right extrapleural pneumothorax. The space was dry two to three weeks after operation.

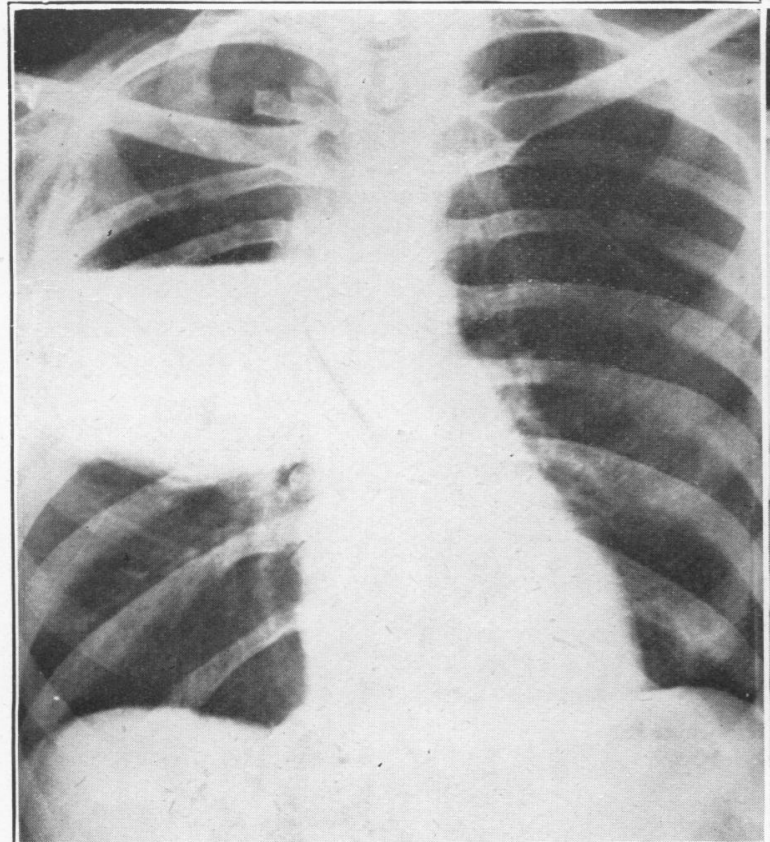

(b) (a)

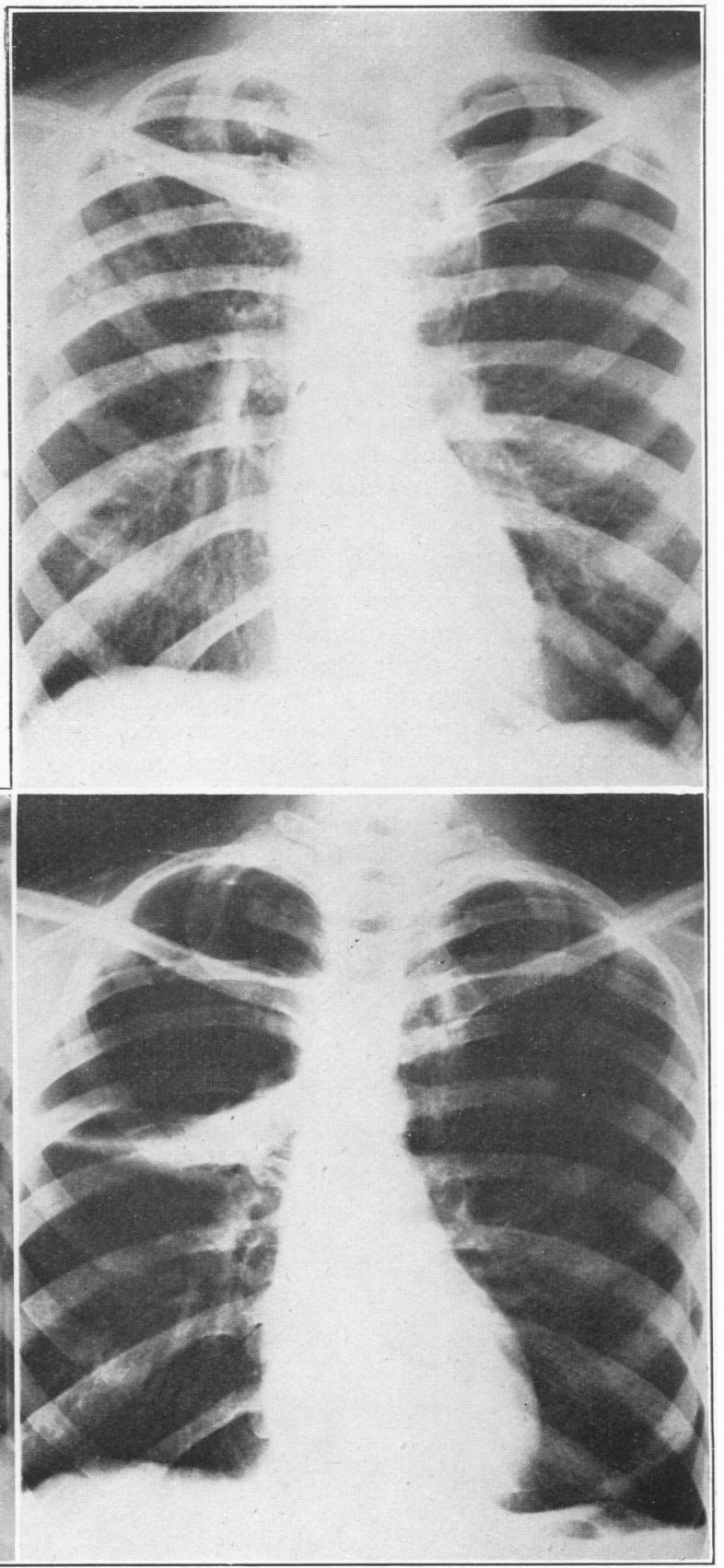

(c) 
space has been painted with the alginate, it is repainted with fresh sponges soaked in 2 per cent calcium chloride. The film of calcium alginate which now lines the cavity is transparent and cannot be seen very well, but the walls glisten and are apparently wet; oozing will have ceased. A little blood may have collected at the bottom during the painting, and this can now be removed. Any excess of alginate or calcium chloride is likewise swabbed out, and the wound closed in the usual way. It is our practice to drop 12 tablets of penicillin into the space before closing the wound. Tablets are used rather than solution, to give a slower rate of absorption and a more prolonged local effect. Sulphathiazole is not used, as it is felt that it may excite a reactionary effusion.

Full general anaesthesia has been used in all the cases save one, in which local anaesthesia only was used.

\section{Postoperative Treatment}

Postoperative treatment consists in leaving the patients in their wards or rooms for three days. Until the morning of the fourth day no aspirations are done, no radiographs are taken, and no refills are given. The patients are discouraged from coughing, and are given one-sixth or a quarter of a grain of morphia every four hours during this first three days. They are put into a sitting position as soon as possible after their return to the ward from the theatre. No case of atelectasis has occurred with this regime.

When the first postoperative radiograph is taken on the fourth day, the space will be found to be a third to half full of liquid. This is aspirated, and recently we have been doing this from the back, as advised by Cleland (1948). The liquid has always been found to be a blood-stained effusion, which flows readily through the needle. Pressures are adjusted to atmospheric. Two or three further aspirations may be required during the next ten days, during which the pressures are kept atmospheric. After the second week the space is dry, and pressures are increased to plus 20 or 30 by the end of the third week. No unfavourable reactions have been experienced, which suggests that the alginate does not have any toxic effects.

I am greatly indebted to Dr. L. E. Houghton, who has referred these cases to me for operation; to Drs. Arnold and Mordasini, of Davos, whose wide experience with, and successful use of, extrapleural pneumothorax stimulated further use of the operation at Harefield, which they visited last year. Arnold uses the heavy postoperative sedation which has been used in this group of cases. In his hands it does not give rise to a high incidence of atelectasis, and there have been no cases of atelectasis in this series.

I am indebted also to Mr. D'Arcy Sutherland-who performed one of the operations, using the technique described-for allowing me to include it in the series; and to Dr. L. G. Blair, who has allowed me to reproduce his radiographs.

\section{REFERENCES}

Blaine, G (1947). Ann. Surg, 125, 102.

Cleland, W. P. (1948). Thorax, 3, 127.

Reid, H. (1946). Thorax, 1, 211. 